\title{
SYNERGISM BETWEEN DIPYRIDAMOLE AND CISPLATIN IN HUMAN BREAST CANCER CELLS in vitro
}

\author{
Janice R. Perussi* \\ Instituto de Química de São Carlos, Universidade de São Paulo, CP 780, 13560-970 São Carlos - SP, Brazil \\ Dina N. Paltoo \\ Cancer Prevention Fellowship Program, National Cancer Institute, 6116 Executive Boulevard, Suite 705, 20892, Baltimore - MD, \\ U.S.A.
}

Veronica A. L. Toppin and Robert G. Canada

Department of Physiology and Biophysics, Howard University College of Medicine, 520 W Street, NW, 20059, Washington - DC, U.S.A.

Recebido em 20/6/02; aceito em 28/10/02

\begin{abstract}
Cisplatin is very effective in the treatment of metastatic breast cancer. However, the development of cellular resistance is a serious problem in cisplatin chemotherapy. In the present work, the effects of dipyridamole (DPM) on the cellular accumulation and cytotoxicity of cisplatin was studied in cisplatin-sensitive (MDA/S) and cisplatin-resistant (MDA/R) human breast cancer cells. In the presence of $30 \mu \mathrm{M} \mathrm{DPM}$, the $\mathrm{IC}_{50}$ of cisplatin was reduced by $39 \%$ for both cell lines. Combination index analysis revealed that cisplatin and dipyridamole interact synergistically in MDA/R cells. In the MDA/S cells, the cellular accumulation of cisplatin increased by $57 \pm 8 \%$ in the presence of $30 \mu \mathrm{M}$ DPM. In the MDA/R cells, the cellular accumulation of cisplatin remained the same with or without $30 \mu \mathrm{M}$ DPM. The results suggest that the enhancement of cisplatin cytotoxicity by DPM in MDA/S cells may be related to a DPM-induced increase in cisplatin accumulation, but the enhanced cytotoxicity in MDA/R cells employs a mechanism that does not involve an increase in the cellular accumulation of cisplatin.
\end{abstract}

Keywords: cisplatin; dipyridamole; synergism.

\section{INTRODUCTION}

Cisplatin is very effective in the treatment of metastatic breast cancer, having an overall response rate around $50 \%{ }^{1-3}$. However, the rapid development of cellular resistance to cisplatin is a serious drawback in using cisplatin as a chemotherapeutic agent ${ }^{4,5}$. Cisplatin resistance is characterized by an enhanced repair of damaged DNA, defective accumulation of the drug and/or increased inactivation of the drug. The various phenotypic expressions of resistance to cisplatin have been addressed by a number of strategies ${ }^{6-8}$. The antitumor activity of cisplatin involves induction of intra- and interstrand crosslinks that severely distort the DNA helix and block replication ${ }^{9-10}$. Since cisplatin accumulation is a major determinant of its antitumor activity, modulators of cisplatin accumulation have received a considerable amount of attention.

Dipyridamole (DPM) has been clinically used as a coronary vasodilator $^{11-13}$. It is best known as an inhibitor of membrane nucleoside transport ${ }^{14}$. Howell et al..$^{15}$ have reported preliminary observations indicating that DPM can increase the sensitivity of human ovarian carcinoma cells to cisplatin. In another investigation, Jekunen et al. ${ }^{16}$, showed that DPM synergistically enhanced the cytotoxicity of cisplatin in cisplatin-sensitive 2008 human ovarian carcinoma cells by a factor of 4.7 , and in the cisplatin-resistant $2008 / \mathrm{C} 13 * 5.25$ subline by a factor of 5.8. DPM was found to increase the cellular uptake of cisplatin in a concentration dependent manner, without increasing trypan blue or propidium iodide uptake or changing cell size. They concluded that the DPM-induced increase in cisplatin accumulation was not associated with a nonspecific increase in membrane permeability. In a nude mouse model with human bladder cancer, Keane et al. ${ }^{17}$, found that tumor size decreased by $20 \%$ when cisplatin was combined with DPM. Using

*e-mail: janice@iqsc.usp.br human testicular carcinoma in the same model, they achieved complete tumor regression. Barberi-Heyob et al. ${ }^{18}$, found that DPM synergistically increased the growth-inhibitory activity of cisplatin in MCF-7 human breast cancer cells. We report here that the enhancement of cisplatin cytotoxicity by DPM in cisplatin-sensitive MDA/S human breast cancer cells suggest that there is a strong correlation between $\mathrm{Pt}$ accumulation and enhanced cisplatin cytotoxicity, but in cisplatinresistant MDA/R cells the synergistic interaction between cisplatin and DPM does not involve an increase in the cellular accumulation of cisplatin.

\section{MATERIALS AND METHODS}

\section{Chemicals}

Cisplatin, cis-diamminedichloroplatinum (II), and dipyridamole, 2,6-bis (diethanolamino)-4,8-dipiperidinopyrimido [5,4-d] pyrimidine, were purchased from SIGMA. Cisplatin stock solutions were made fresh $24 \mathrm{~h}$ before each experiment in unsupplemented medium to minimize the hydrolysis of cisplatin into the aquated species. Dipyridamole stock solutions were prepared in dimethylsulfoxide (DMSO) and kept in the dark at $4{ }^{\circ} \mathrm{C}$. Drug solutions were sterilized via syringe filtration just before use. Calcein-AM (calcein acetoxylmethylester) was purchased from Molecular Probes. All chemicals were of analytical quality and were used as received.

\section{Cell cultures}

Dr. P. A. Andrews (Cato Research, Rockville, MD, USA) donated the cisplatin-sensitive (MDA/S) and cisplatin-resistant (MDA/R) variants of the MDA-MB-231 human breast cancer cell line. The cells were grown as a monolayer in $75 \mathrm{~cm}^{2}$ flasks with Minimal 
Essential Medium (Earle's salts) supplemented with L-glutamine, $10 \%$ fetal bovine serum, non-essential amino acids $(1 \mathrm{x})$, sodium pyruvate $(1 \mathrm{mM})$ and insulin $(10 \mu \mathrm{g} / \mathrm{ml})$ at $37{ }^{\circ} \mathrm{C}$ in a humidified atmosphere of $5 \% \mathrm{CO}_{2}$ in $95 \%$ air. Confluent cell cultures were harvested with 1:5000 Versene and washed twice with unsupplemented medium. Cells were counted using a hemocytometer and viability was assessed by the trypan blue exclusion method.

\section{Live cell microfluorometric assay}

As previously described, the cytotoxicity of cisplatin was determined by a live cell microfluorometric assay ${ }^{19}$. MDA/S and $\mathrm{MDA} / \mathrm{R}$ cells were seeded in 6-multiwell culture plates at 10,000 cells/well. The cells were treated with either $0,25,50,75,150$ or $250 \mathrm{mM}$ cisplatin in unsupplemented medium, with or without $30 \mu \mathrm{M}$ DPM, for $60 \mathrm{~min}$ at $37{ }^{\circ} \mathrm{C}$ and $5 \% \mathrm{CO}_{2}$, then incubated for 3 days in ordinary supplemented medium. DPM is insoluble in aqueous solutions at concentrations above $30 \mu \mathrm{M}$. All drug concentrations were set in duplicate. The cells were allowed to interact with $3 \mu \mathrm{M}$ calcein-AM in Dulbecco's phosphate-buffered saline for $60 \mathrm{~min}$ at room temperature. The fluorescence intensity of each well was read at $530 \mathrm{~nm}($ exc. $=485 \mathrm{~nm})$ using a Cambridge Technology Microplate Fluorometer Model 7630. The live cell intensity without $\operatorname{drug}(\mathrm{s})$, i.e., at $0.0 \mu \mathrm{M}$ cisplatin and $0.0 \mu \mathrm{M}$ DPM, was regarded as the control live cell intensity at $100 \%$ cell survival. An index of survival was calculated at each cisplatin concentration, as the quotient of the live cell intensity with drug divided by the control live cell intensity without drug.

\section{Median-effect principle for dose-effect analysis}

The multiple drug effect analysis of Chou and Talalay ${ }^{20}$, which is commercially available as the Calcusyn computer program developed by Chou and Hayball ${ }^{21}$, was used to obtain the cytotoxic parameters (i.e., $\mathrm{IC}_{20}, \mathrm{IC}_{50}$ and $\mathrm{IC}_{80}$ ) and to construct the theoretical curves. Data were graphically visualized by plotting the index of cell survival against its corresponding cisplatin concentration. The degree of synergism between cisplatin and DPM was determined by using combination index (CI) analysis at a non-constant ratio, i.e., drug combinations were made by varying the concentrations of one drug (cisplatin) while keeping the second drug (dipyridamole) concentration fixed. An average CI $<1$ indicates synergism, $>1$ indicates antagonism and an average $\mathrm{CI}$ of 1 indicates additivity.

\section{Statistical analysis}

Data values are reported as the mean \pm the standard error of the mean (SEM). Student's unpaired t-test was used to evaluate differences between pairs of means. Two-way analysis of variance (ANOVA) was used to evaluate differences between pairs of survival curves. The degree of significance for the data is presented as probability $(P)$ values; the accepted level of significance is $\mathrm{P}<0.05$.

\section{Determination of cisplatin accumulation in the presence of DPM}

The cellular accumulation of cisplatin has been described in detailed elsewhere ${ }^{22}$. Briefly, cells were seeded into $60 \mathrm{~mm}$ plastic culture dishes and grown to confluence as monolayers in ordinary supplemented medium at $37^{\circ} \mathrm{C}$ and $5 \% \mathrm{CO}_{2}$. The cells were incubated with $200 \mu \mathrm{M}$ cisplatin in the presence of $0,5,15$ or $30 \mu \mathrm{M}$ dipyridamole in unsupplemented medium for $60 \mathrm{~min}$ at $37^{\circ} \mathrm{C}$, then washed four times with ice-cold phosphate buffered saline. Next, $1.0 \mathrm{ml}$ of $0.1 \%$ Triton $\mathrm{X}-100$ in $0.1 \mathrm{~N} \mathrm{HCl}$ was added to each dish; the cells were scraped from the bottom surface. The detached cells were frozen in cryogenic vials for at least $24 \mathrm{~h}$. Upon thawing, the cells were sonicated at 7 watts with a Branson Sonifer Model 450 (Branson Sonic Power, Danbury, CT). Twenty $\mu \mathrm{L}$ aliquots of the lysate were used for platinum analysis in a Perkin-Elmer Zeeman Atomic Absorption Spectrometer Model 4110ZL (Perkin-Elmer, Norwalk, CT). Cisplatin accumulation is expressed as picomoles of platinum per milligram of protein.

\section{RESULTS}

\section{Cisplatin alone and combined with dipyridamole}

Figure 1 shows the indices of cell survival for the cisplatin-sensitive MDA/S and cisplatin-resistant MDA/R cells as a function of the cisplatin concentration, in the absence and presence of $30 \mu \mathrm{M}$ DPM. At each cisplatin concentration, the indices of survival for the MDA/ $\mathrm{S}$ and MDA/R cells were reduced in the presence of DPM. In both cells lines, the survival curve for cisplatin alone is significantly different from that with $30 \mu \mathrm{M}$ DPM $(\mathrm{P}<0.003$ for MDA/S cells and $\mathrm{P}<0.001$ for MDA/R cells). However, the survival curve for the cisplatin-resistant MDA/R cells with DPM is practically the same as the survival curve for the cisplatin-sensitive MDA/S cells $(\mathrm{P}>0.6)$. These findings suggest that the cytotoxicity of cisplatin is increased in the presence of DPM. Further, DPM appears to have increased the cytotoxicity of cisplatin in cisplatin-resistant MDA/R cells to the level of that in cisplatin-sensitive MDA/S cells. Table 1 illustrates the difference between the cytotoxic parameters for cisplatin alone versus those for cisplatin combined with $30 \mu \mathrm{M}$ DPM. In the MDA/ $\mathrm{S}$ cells, DPM reduced the $\mathrm{IC}_{20}, \mathrm{IC}_{50}$ and $\mathrm{IC}_{80}$ values of cisplatin by $25 \%, 39 \%$ and $56 \%$, respectively, indicating that the degree of enhancement of cisplatin cytotoxicity by DPM increased with cisplatin concentration. On the other hand, in cisplatin-resistant MDA/ $\mathrm{R}$ cells, the enhancement of cisplatin cytotoxicity by DPM decreased with cisplatin concentration. In MDA/R cells, DPM reduced the cisplatin $\mathrm{IC}_{20}, \mathrm{IC}_{50}$ and $\mathrm{IC}_{80}$ values by $57 \%, 39 \%$ and $6 \%$, respectively.

Figure 2 shows the sensitivity of the cells to DPM alone. The survival of MDA/S cells was reduced by $10 \%$ in the presence of

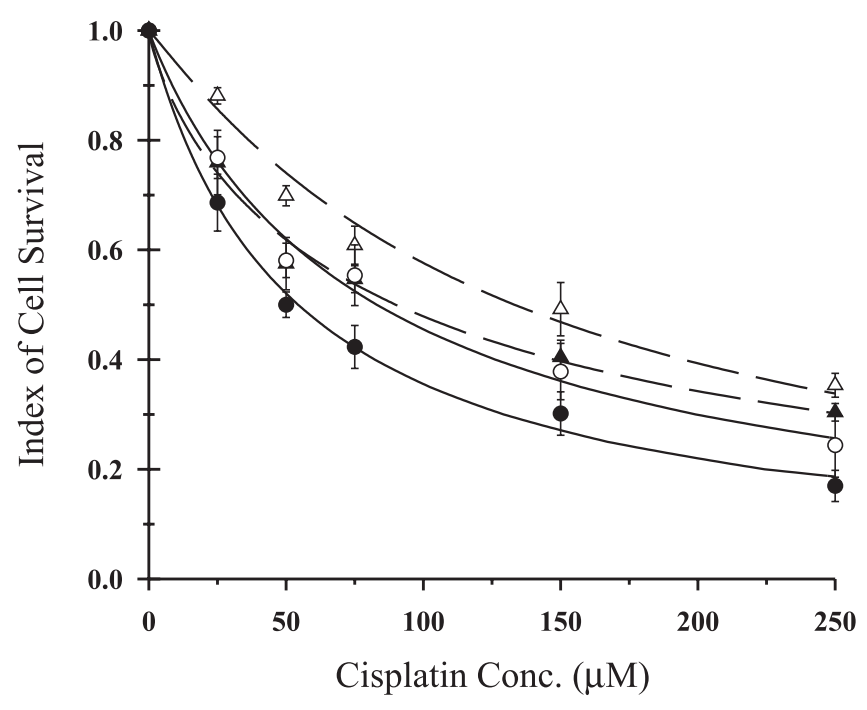

Figure 1. Index of cell survival of cisplatin-sensitive MDA/S cells in the absence (open circles) or presence (closed circles) of $30 \mu M D P M$ and cisplatin-resistant $M D A / R$ cells in the absence (open triangles) or presence (closed triangles) of $30 \mu M D P M$, as a function of the cisplatin concentration. Each data point represents the mean \pm SEM of five experiments performed in duplicate 
Table 1. The effects of $30 \mu \mathrm{M}$ DPM on the cytotoxicity of cisplatin in cisplatin-sensitive MDA/S and cisplatin-resistant MDA/R cells. Cisplatin cytotoxic parameters are expressed as the mean \pm SEM; $\mathrm{n}=5$

\begin{tabular}{lcccc}
\hline Cell Line & {$[\mathrm{DPM}]$} & \multicolumn{3}{c}{ Cytotoxic Parameter $(\mu \mathrm{M})$} \\
\cline { 3 - 5 } & & $\mathrm{IC}_{20}$ & $\mathrm{IC}_{50}$ & $\mathrm{IC}_{80}$ \\
\hline MDA/S & & & & \\
& $0.0 \mu \mathrm{M}$ & $20 \pm 4$ & $92 \pm 22$ & $525 \pm 298$ \\
MDA/R & $30 \mu \mathrm{M}$ & $15 \pm 6$ & $56 \pm 13$ & $229 \pm 47$ \\
& & & & \\
& $0.0 \mu \mathrm{M}$ & $37 \pm 3$ & $145 \pm 32$ & $609 \pm 206$ \\
& $30 \mu \mathrm{M}$ & $16 \pm 5$ & $89 \pm 17$ & $571 \pm 124$ \\
\hline
\end{tabular}

$30 \mu \mathrm{M}$ DPM. However, this reduction was not statistically significant $(P>0.1)$. An inhibitory concentration of DPM could not be determined, because the solubility of DPM is very low in aqueous solutions. Consequently, a quantitative analysis into the nature of the interaction between cisplatin and DPM was not possible in the MDA/S cell line. Since DPM does not appreciably affect the survival of MDA/S cells, it is assumed that the interaction between cisplatin and DPM in these cells is synergistic in nature. The survival of MDA/ $\mathrm{R}$ cells was significantly reduced by $15 \%$ in the presence of $30 \mu \mathrm{M}$ DPM $(\mathrm{P}<0.02)$. The $\mathrm{IC}_{50}$ value of DPM was estimated to be $394 \mu \mathrm{M}$. The cytotoxic effect of cisplatin is 2.7 times more potent than that of DPM in MDA/R cells; DPM has a low cytotoxicity. Combination index analysis indicated that the interaction between cisplatin and DPM is synergistic at intermediate indices of cell death (i.e., fractions affected) (Table 2).

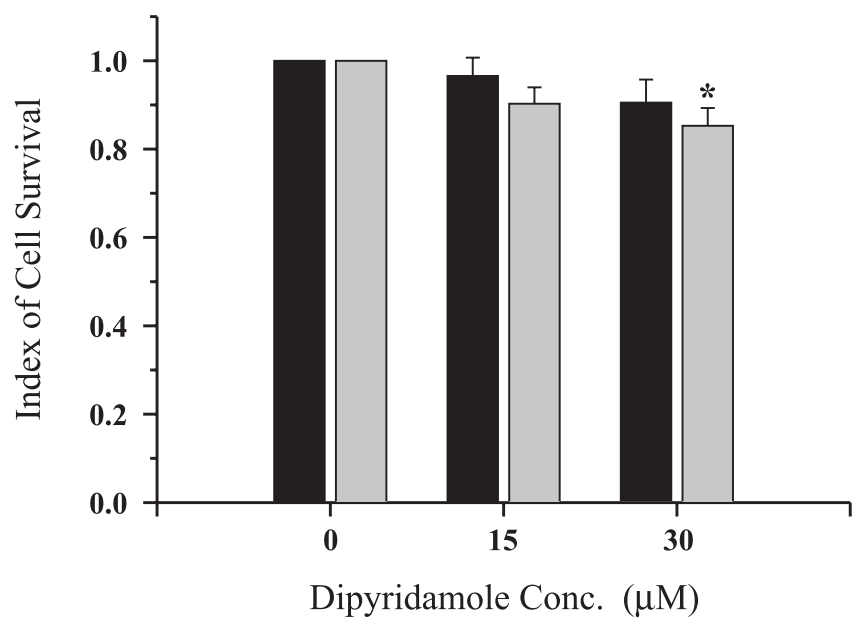

Figure 2. Index of cell survival of cisplatin-sensitive MDA/S cells (black bars) and cisplatin-resistant MDA/R cells (gray bars) in the presence of dipyridamole alone. Each data point represents the mean \pm SEM of two experiments performed in duplicate

\section{Cellular accumulation of cisplatin with dipyridamole}

The effects of DPM on the cellular accumulation of cisplatin are shown in Figure 3. A two-way ANOVA revealed that between the two cell lines, there was a significant group difference in the cellular accumulation of cisplatin with respect to the DPM concentration $(\mathrm{P}<$ 0.001). The cisplatin-resistant MDA/R cell line displayed a defective accumulation of cisplatin. At $0.0 \mu \mathrm{M}$ DPM, the accumulation of cisplatin in MDA/R cells at $107 \pm 5 \mathrm{pmol} \mathrm{Pt} / \mathrm{mg}$ Protein was $68 \%$ less
Table 2. Combination index analysis of cisplatin combined with $30 \mu \mathrm{M}$ DPM at a non-constant ratio in cisplatin-resistant MDA/R cells. Data are of values from Figure 1. [cisplatin] = Cisplatin Concentration, $\mathrm{F}_{\mathrm{a}}=$ Fraction affected and $\mathrm{CI}=$ Combination Index.

\begin{tabular}{cccl}
\hline [cisplatin] & $\mathrm{F}_{\mathrm{a}}$ & $\mathrm{CI}$ & Description* \\
\hline $25 \mu \mathrm{M}$ & 0.24 & 0.96 & Nearly additive \\
$50 \mu \mathrm{M}$ & 0.42 & 0.62 & Synergism \\
$75 \mu \mathrm{M}$ & 0.45 & 0.77 & Moderate synergism \\
$150 \mu \mathrm{M}$ & 0.60 & 0.83 & Moderate synergism \\
$250 \mu \mathrm{M}$ & 0.70 & 0.89 & Slight synergism \\
\hline
\end{tabular}

$* \mathrm{CI}=1.00$, additive; $\mathrm{CI}<1.00$, synergistic $; \mathrm{CI}>1.00$, antagonistic

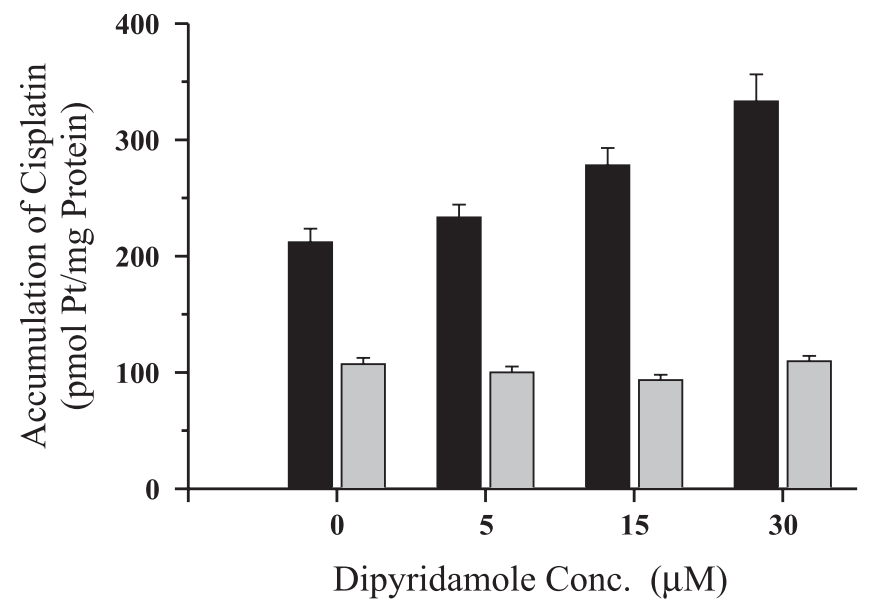

Figure 3. The effects of dipyridamole on the cellular accumulation of cisplatin in cisplatin-sensitive MDA/S cells (black bars) and cisplatinresistant MDA/R cells (gray bars). Each bar represents the mean \pm SEM of three experiments performed in triplicate

than the cisplatin accumulation in MDA/S cells at $212 \pm 12 \mathrm{pmol} \mathrm{Pt} /$ $\mathrm{mg}$ Protein. The accumulation of cisplatin in MDA/S cells significantly increased as a function of the DPM concentration $(\mathrm{P}<0.001)$; at 30 $\mu \mathrm{M}$ DPM, the cellular accumulation of cisplatin increased by $57 \pm 8 \%$ to $333 \pm 23 \mathrm{pmol} \mathrm{Pt} / \mathrm{mg}$ Protein. In MDA/R cells, the accumulation of cisplatin did not clearly change with the DPM concentration $(\mathrm{P}>0.08)$; the cellular accumulation of cisplatin was $110 \pm 5 \mathrm{pmol} \mathrm{Pt} / \mathrm{mg}$ Protein at $30 \mu \mathrm{M}$ DPM. Our data suggest that DPM may enhance the antitumor action of cisplatin by modulating the cellular accumulation of cisplatin in MDA/S cells. In the cisplatin-resistant MDA/R subline, the increase in cisplatin cytotoxicity does not appear to correlate with a change in cisplatin accumulation.

\section{DISCUSSION}

The development of cisplatin resistance is a major problem in treating patients with cisplatin chemotherapy. A number of agents have been shown to reverse cisplatin resistance in vitro; for example, calcium channel blockers and DPM increase the cellular accumulation of cisplatin ${ }^{23}$; hydroxyurea reduces DNA repair by decreasing the pool of deoxy-ribonucleotides; buthionine sulfoximine blocks the de novo synthesis of glutathione by inhibiting $\gamma$-glutamylcysteine synthetase $^{24}$. One fact emerges from these various strategies is that the cytotoxic activity of cisplatin is proportional to its intracellular concentration. Some authors have hypothesized that the transport of cisplatin into the cell involves a combination of passive and facilitated diffusion $^{6,25}$. DPM has been shown to enhance the cellular 
accumulation and cytotoxicity of cisplatin in human ovarian, bladder and testicular cancer cell lines. The clinical importance of DPM is illustrated by its low toxicity and well-characterized inhibition of nucleoside transport ${ }^{26}$. In this report, we present evidence suggesting that DPM can increase the cytotoxicity of cisplatin in cisplatinsensitive and cisplatin-resistant human breast cancer cells. The enhancement of cisplatin cytotoxicity by DPM is greater at intermediate indices of cell survival, and is most likely due to a synergistic interaction between cisplatin and DPM. In MDA/S cells, the cellular accumulation of cisplatin increased by $60 \%$ in the presence of 30 $\mu \mathrm{M}$ DPM, while the cisplatin $\mathrm{IC}_{50}$ value decreased by $40 \%$. This insinuates that the increased cytotoxicity of cisplatin by DPM may be due to an increased accumulation of cisplatin into the cells. In the MDA/R cells, the cellular accumulation of cisplatin remained the same in the absence and presence of $30 \mu \mathrm{M}$ DPM, even though the cisplatin $\mathrm{IC}_{50}$ value decreased by $40 \%$. This suggests that the enhancement of cisplatin cytotoxicity by DPM in MDA/R cells employ a mechanism that does not involve an increase in the cellular accumulation of cisplatin. Mack et al. ${ }^{27}$, have suggested that cisplatin resistance in MDA-MB-231 human breast cancer cells may in part be due to an increase in the detoxification of cisplatin via elevated levels of glutathione.

The enhancement of DNA repair is a cellular response to cisplatin resistance and, to achieve higher levels of resistance, the cell induces mechanisms that affect drug accumulation and/or detoxification ${ }^{28}$. In some cisplatin-resistant cell lines, the defective accumulation of cisplatin has been attributed to an active efflux system for cisplatin ${ }^{29}$. An ATP-dependent glutathione S-conjugate export pump has been reported to play a key role in removing the bis-(glutathionato)platinum(II) complex from cancer cells ${ }^{30}$. Perhaps, the defective accumulation of cisplatin in the MDA/R cells is due to an elevated active efflux system involving glutathione and cisplatin.

The potentiation of a variety of multidrug resistance (MDR) drugs by DPM have been demonstrated and evidence supports the fact that this effect is mediated via an interaction of DPM with the P-glycoprotein (P-gp), a plasma membrane efflux pump that is overexpressed in many cells with the MDR phenotype. However, the P-gp is not involved in cisplatin resistance ${ }^{29}$. Turner and Curtin $^{31}$ showed that the effect of DPM was similar in both parental and P-gp overexpressing cells and concluded that the potentiation of etoposide by DPM is unlikely to be mediated via an interaction with P-gp. They suggested that another drug efflux protein might be the target for DPM.

It is possible that DPM can form an active complex with cisplatin $^{23}$. When tested in MDA-MB-468 (breast carcinoma) and HL-60 (leukemia) human cancer cell lines, a synthetic Pt-DPM ionic complex altered the electrophoretic mobility of DNA to a lower extent than cisplatin alone, and it had a higher antiproliferative activity (3fold) than cisplatin ${ }^{23}$. The authors concluded that in the Pt-DPM ionic complex, the DPM residues synergistically enhance the cytotoxicity of the Pt by increasing the cellular Pt uptake.

The mechanism by which DPM increases the cytotoxicity of cisplatin is still unclear but it appears that DPM interacts with the cell membrane in such a way so as to increase the intracellular accumulation of cisplatin. DPM and its derivatives have been shown to interact with membrane biomimetic model systems such as micelles, phospholipid monolayers and vesicles as well as with proteins $^{32}$. A clinical evaluation of cisplatin and dipyridamole in gastric cancers has been performed ${ }^{33}$. The coadministration of cisplatin and DPM is feasible and may permit the treatment of breast cancer patients with cisplatin concentrations that are effective in killing cisplatin-resistant breast cancer cells without inducing the severe side effects of high drug concentrations. Thus, resistance to cisplatin may be reversed.

\section{ACKNOWLEDGEMENTS}

The authors would like to thank Dr. M. Tabak for his critical reading of the manuscript.

\section{LIST OF ABREVIATIONS}

$\begin{array}{ll}\text { DPM } & \text { dipyridamole } \\ \text { MDA/S } & \text { cisplatin-sensitive human breast cancer cells } \\ \text { MDA/R } & \text { cisplatin-resistant human breast cancer cells } \\ \text { DMSO } & \text { dimethylsulfoxide } \\ \text { Calcein-AM } & \text { calcein acetoxylmethylester }\end{array}$

\section{REFERENCES}

1. Sledge, G.; Semin. Oncol. 1992, 19, 78.

2. Tolcher, A.; Semin. Oncol. 1996, 23, 37.

3. Wasserheit, C.; Frazein, A.; Oratz; R.; Sorich, J. Downey, A.; Hochster, H.; Chachoua, A.; Wernz, J.; Zeleniuch-Jacquatte, A.; Blum, R.; Speyer, J.; J. Clin. Oncology 1996, 14, 1993.

4. Ozols, R. F.; Young, R. C.; Semin. Oncol. 1991, 18, 222.

5. Inoue, K.; Mukaiyama, T. M.; Mitsui, I.; Ogawa, M.; Cancer Chemother Pharmacology 1985, 15, 208.

6. Gately, D. P.; Howell, S. B.; Br. J. Cancer 1993, 67, 1171.

7. Andrews, P. A.; Howell, S. B.; Cancer Cells 1990, 2, 35.

8. Ford, J. M.; Hait, W. N.; Pharmacol. Rev. Commun. 1990, 42, 155.

9. Zamble, D. B.; Lippard, S. J.; Trends Biochem. Sci. 1995, 20, 435.

10. Pillaire, M. J.; Hoffmann, J. S.; Defais, M.; Villani, G.; Biochimie 1995, 77, 803 .

11. Marchandt, E.; Pichard, A. D.; Casanegra, P.; Lindsay, L.; Am. J. Cardiol. 1984, 53, 718.

12. Fitzgeralde, G. A.; New England J. Medicine 1987, 316, 1247.

13. Batisda, E.; del Prado, J.; Almirall, L.; Janieson, G. A.; Ordinas, A.; Cancer Res. 1985, 45, 4048.

14. Plagemann, P. G. W.; Wohlhueter, R. M.; Woffendin, C.; Biochim. Biophys. Acta 1988, 947, 405

15. Howell, S. B.; Vick, J.; Andrews, P. A.; Velury, S.; Sanga, R.; Platinum and Other Metal Coordination Compounds in Cancer Chemotherapy, Martinus N. Publ.: Boston, MA, 1987.

16. Jekunen, A.; Vick, J.; Sanga, R.; Chan, T. C. K.; Howell, S.B.; Cancer Res. 1992, 52, 3566.

17. Keane, T. E.; Rosner, G.; Donaldson, J. T.; Norwood, D. L.; Poulton, S. H.; Walther P. J.; J. Urology 1990, 144, 1004.

18. Barberi-Heyob, M.; Giffon, G.; Merlin, J.L.; Weber, B.; Cancer Chemother. Pharmacol. 1993, 33, 163.

19. Fuller, T.; Canada, R.; Cancer Chemother. Pharmacol. 1999, 44, 249.

20. Chou, T. C.; Talalay, P. In Advances in Enzyme Regulation; Weber, G., ed.; Pergamon Press: New York, 1983.

21. Chou, T. C.; Hayball, M.; CalcuSyn: Windows software for dose effect analysis, Biosoft: Cambridge, 1996.

22. Andrews, P. A.; Murphy, M.; Howell, S.; Eur. J. Cancer Clin. Oncol. 1989, $25,619$.

23. López-Solera, I.; Pérez, J.; Monge, M.; Alvarez-Valdés, A.; Masaguer, J. R.; Alonso, C.; Navarro-Ranninger, C. ; J. Inorg. Biochem. 1994, 56, 233.

24. Gosland, M.; Lum, B.; Schimmelpfennig, J.; Baker, J.; Doukas, M.; Pharmacother. 1996, 16, 16.

25. Los, G.; Gately, D.; Costello, ML.; Thiebaut, F.; Naredl, P.; Howell, S. B.; Platinum and Other Metal Coordination Compounds in Cancer Chemotherapy 2, Plenum Press: New York, 1996.

26. Schmoll, H.; Harstrick, A.; Kohne-Wompner, C.; Schober, C.; Wilke, H.; Poliwoda, H.; Cancer Treat. Ver. 1990, 17, 57.

27. Mack, K. M.; Canada, R. G.; Andrews, P. A.; Cancer Chemother. Pharmacol. 1997, 39, 217.

28. Chao, C. C. K.; J. Formos. Med. Assoc. 1996, 95, 893.

29. Komatsu, M.; Sumizawa, T.; Mutoh, M.; Chen, Z.; Terada, K.; Furukawa, T.; Yang, X.; Gao, H.; Miura, N.; Sugiyama, T.; Akiyama, S.; Cancer Res. 2000, 60, 1312.

30. Chen, Z. S.; Mutoh, M.; Sumizawa, T.; Furukawa, T.; Haraguchi, M.; Tani, A.; Saijo, N.; Kondo, T.; Akiyama, S. I.; Exp. Cell Res. 1998, 240, 312.

31. Turner, R. N.; Curtin, N. J.; Br. J. Cancer 1996, 73, 856.

32. Borissevitch, I. E.; Borges, C. P. F.; Borissevitch, G. P.; Yushmanov, V. E.; Louro, S. R. W.; Tabak, M.; Z. Naturforsch C: J. Biosci. 1996, 51, 578.

33. Kohnoe, S.; Maehara, Y.; Takahashi, I.; Emi, Y.; Baba, H.; Sugimachi, K.; Int. J. Oncol. 1998, 13, 1203. 